\title{
SLEEP DISTURBANCE AND QUALITY OF SLEEP AMONG PATIENTS WITH CARDIOVASCULAR DISEASES
}

\author{
NEENU MERIN ${ }^{1}$, REGINA ANTONY ${ }^{2}$ \\ ${ }^{1}$ M. Sc Nursing Student, Amrita College of Nursing, Amrita Vishwa vidyapeetham, Kochi, Kerala, India, ${ }^{2}$ Department of Medical Surgical \\ Nursing, Amrita College of Nursing, Amrita Vishwa vidyapeetham, Kochi, Kerala, India. Email: reginaantony@aims.amrita.edu
}

Received: 25 July 2018, Revised and Accepted: 17 October 2018

\section{ABSTRACT}

Objective: This was a descriptive study with the objective to determine the sleep disturbances and the quality of sleep among patients with cardiovascular diseases (CVDs).

Methods: Quantitative approach with non-experimental descriptive design was used. A semi-structured sleep disturbance questionnaire was used to determine the sleep disturbances, and a standardized Pittsburgh Sleep Quality Index tool was used to assess the sleep quality among 100 subjects in Amrita Institute of Medical Sciences, Kochi.

Results: The study results showed that majority of the subjects (51\%) were of the age group between 56 and 65 years, and $71 \%$ were male with CVD. Sleep disturbances were present in $80 \%$ of the subjects with CVD, among which $56 \%$ subjects had mild disturbances, $20 \%$ subjects with moderate sleep disturbances, and $4 \%$ subjects with severe sleep disturbances. The result also indicated that $48 \%$ of subjects had poor sleep quality. Findings also showed a highly statistically significant association between cardiomyopathy and sleep disturbances $(\mathrm{p}<0.001)$. Total cholesterol and low-density cholesterol levels were significantly associated with sleep disturbances $(\mathrm{p}<0.05)$. There is a highly significant association between sleep disturbances and quality of sleep $(\mathrm{p}<0.001)$, indicating that sleep disturbances can be one factor in decreasing the quality of sleep in patients with CVD.

Conclusion: The results of the study indicated that sleep disturbances were prevalent in patients with CVD and often hazardous to heart health. As health practitioner and other health-care providers have not focused major attention on the importance of sleep to health, the need for providing information to them and patients regarding the importance of improving the quality of sleep and identifying the sleep disturbances will call for action to bring sleep to the forefront of public health.

Keywords: Sleep disturbances, Quality of sleep, Cardiovascular disease.

(C) 2019 The Authors. Published by Innovare Academic Sciences Pvt Ltd. This is an open access article under the CC BY license (http://creativecommons. org/licenses/by/4. 0/) DOI: http://dx.doi.org/10.22159/ajpcr.2019.v12i12.28622

\section{INTRODUCTION}

Sleep is essential for a healthy heart [1]. Irregular or insufficient sleep can ultimately endanger heart health. Almost everyone has trouble sleeping once in a while, but if occasional episodes of sleep escalate into an unhealthy night time routine, it will hamper the productivity and sap the patient's quality of life. Studies show that, compared to sleep duration of $7 \mathrm{~h}$, both short and long durations of sleep ( $\leq 5$ and $\geq 9 \mathrm{~h}$ ) were positively associated with cardiovascular disease (CVD) in a large, nationally representative sample of the US adults [2]. Many studies have shown the relationship between sleep apnea and CVD. It was identified and found that over an 8-year period, men with severe sleep apnea were $58 \%$ more likely to develop congestive heart failure than men without the nighttime breathing disorder. Poor sleeping as a result of changing work schedules or poor sleep habits can put at risk as well [3].

It is understood that sleeping too little causes disruptions in underlying health conditions and biological processes such as glucose metabolism, blood pressure, and inflammation. In the National Health Interview Survey 2004-2007, more than one-third of the population in the US was reported to have an abnormal sleep duration, defined as either a short or long sleep duration. Several studies have shown that, compared to 7-8 h of sleep, both shorter and longer sleep durations are associated with CVD risk factors such as diabetes, hypertension, and obesity $[3,4]$. The cost of poor sleep is much greater, and it may have profound consequences for our long-term health. Research has revealed that people who consistently fail to get enough sleep are at an increased risk of chronic disease. Treating sleep as a priority, rather than a luxury, may be an important step in preventing a number of chronic medical conditions. Sleep complaints increase with age, and they are twice as prevalent in women compared to men [5].

Globally, in 2015, there were estimated 422.7 million prevalent cases of CVD which is recorded. Countries with the lowest age-standardized prevalence of CVD in 2015, all with $<5000$ cases per 100,000 individuals, included Singapore, Japan, South Korea, Chile, Argentina, Uruguay, Canada, Australia, New Zealand, Ireland, Cyprus, Malta, Italy, Greece, and Israel. Countries in Western Europe, as well as the United States, the United Arab Emirates, and Nepal, all had only slightly higher prevalence. Countries with the highest age-standardized prevalence in 2015, all $>9000$ cases per 100,000 persons, included most countries in West Africa, Morocco, Iran, Oman, Zambia, Mozambique, and Madagascar [6].

In 2011, there were 82,771 deaths by acute myocardial infarction (MI) (AMI) in Brazil, $46.7 \%$ in the Southeast. Data from the USA estimate that there are approximately 525,000 new cases and 190,000 recurring cases of AMI yearly, with a mean age of 64.7 and 72.2 years for men and women, respectively, which shows the magnitude of the disease. Poor sleep quality and disorders are considered additional risk factors for CVD and AMI. Many authors point out that changes in the duration of sleep ( $<5 \mathrm{~h}$ and $>9 \mathrm{~h}$ ) are related to an increased risk of developing and/ or dying of coronary disease and AMI. Other studies show that $<6 \mathrm{~h}$ of sleep per night, or $<7 \frac{1}{2} \mathrm{~h}$ for diabetic patients, represent a higher risk for AMI [7].

In a prospective cohort study, duration of sleep equal to or higher than $7 \mathrm{~h}$, associated with other four lifestyle factors (physical activity, healthy 
diet, moderate use of alcohol, and no smoking), was related to a lower risk of CVD. CVDs are the number one cause of death globally: More people die annually from CVDs than from any other cause. An estimated 17.7 million people died from CVDs in 2015, representing 31\% of all global deaths. Of these deaths, an estimated 7.4 million were due to coronary heart disease (CHD) and 6.7 million were due to stroke. Over three-quarters of CVD deaths take place in low- and middle-income countries [7]. India will soon bear the largest burden of heart disease globally: In India, of the estimated population of $>1.27$ billion dispersed across various geographical regions, about 45 million people suffer from coronary artery disease (CAD). 'According to current estimates, India will soon have the highest number of cases of CVD in the world', says Dr. Nikhil Kumar, Director, Cardiology, Fortis Memorial Research Institute, Gurgaon. It is estimated to account for $35.9 \%$ deaths by the year 2030 [8].

In Kerala, $14 \%$ of all deaths are caused by CHD/CAD. In Kerala, the prevalence of lifestyle diseases such as diabetes, heart disease, high blood pressure, and obesity is high, and it results in very high mortality and morbidity from malignant heart disease [8]. In Kerala, mortality rates for CAD per 100,000 are 382 for men and 128 for women which are actually 3-6 times higher than Japanese and rural Chinese and also higher than other industrialized countries. Approximatelyw $60 \%$ of CAD deaths in men and $40 \%$ of CAD deaths in women occur before the age of 65 years that is at very young age. People from Kerala have the highest cholesterol level in India which ranges from 197 to $229 \mathrm{mg} / \mathrm{dl}$ compared to 157 to $180 \mathrm{mg} / \mathrm{dl}$ nationally. Kerala is known as the diabetes capital of India as the prevalence of diabetes is high, i.e., $20 \%$ which is double the national average of $8 \%$. As compared, the prevalence in Thiruvananthapuram was 17\%, in Hyderabad and New Delhi 15\%, in Nagpur 4\%, and in Dibrugarh 3\% [9].

The cardiology unit of Amrita Institute of Medical Sciences and Research Centre, Kochi, has a monthly censes of the average of 797 new cases and 2919 revisits. The sleep laboratory studies in Amrita Institute of Medical Sciences and Research Centre, Kochi, have an yearly censes of 132 patients and among that 18 cases were patients with CVDs.

\section{METHODS}

A quantitative approach and a non-experimental descriptive design study was conducted in Cardiology out-patient department and cardiology ward of Amrita Institute of Medical Sciences and Research Centre, a tertiary care center hospital, Kochi, among 100 subjects using non-probability convenient sampling technique. The setting was selected because of the easy accessibility of the group, familiarity with setting, convenience in terms of adequate sample, and the cooperation offered by the management. The researcher explained the purpose of the study and obtained an informed consent from each subject. The tool for data collection include Tool I - Semi-structured questionnaire consists of two sections, Section I: Sociodemographic data and clinical data and Section II: Sleep disturbance questionnaire to assess the sleep disturbances among patients with CVDs, and Tool II - Pittsburgh Sleep Quality Index (PSQI) to assess the quality of sleep among patients with CVD. Data analysis was performed using descriptive and inferential statistics.

\section{RESULTS}

Section I: Description of sociodemographic variables of the subjects

The data presented in Table 1 is regarding the sociodemographic characteristics showed that, among the 100 subjects, 59 (59\%) patients with CVDs were in the age group of 56-65 years, followed by $27(27 \%)$ between 46 and 55 years, and $71(71 \%)$ were males and $97(97 \%)$ were married. Among the 100 subjects, 49 (49\%) of them had high-school education, 35 (35\%) of the subjects were employed, and maximum number of subjects $36(36 \%)$ were having monthly income of greater than Rs. 15,000.

B: Description of sample characteristics based on clinical variables The clinical variables include diagnosis, duration of cardiac illness, family history of cardiac illness and presence of co-morbidities, use of prescribed medications, habit of snoring, smoking habit, alcoholism, body mass index (BMI), neck circumference, waist-hip ratio, and intervention undergone.

The data presented in Table 2 regarding the clinical characteristics showed that the majority of the subjects, 44 (44\%), had the duration of cardiac illness for $>5$ years, only $21(21 \%)$ subjects had family history of cardiac illness, and $9(9 \%)$ among the subjects had the habit of smoking; however, 27 (27\%) stopped smoking and $11(11 \%)$ subjects had the habit of alcoholism. Regarding the BMI, 61 (61\%) subjects had a higher BMI than the normal range, of which $14(14 \%)$ subjects were obese and nearly 47 (47\%) subjects were overweight.

Table 1: Frequency and percentage distribution of subjects based on demographic characteristics, $n=100$

\begin{tabular}{ll}
\hline Sociodemographic variables & Frequency (f) (\%) \\
\hline Age in years & \\
$36-45$ & $5(5)$ \\
$46-55$ & $27(27)$ \\
$56-65$ & $59(59)$ \\
$66-75$ & $9(9)$ \\
Gender & $71(71)$ \\
Male & $29(29)$ \\
Female & \\
Educational status & $8(8)$ \\
Primary & $49(49)$ \\
High school & $16(16)$ \\
Pre-degree/plus-two/equivalent & $24(24)$ \\
Graduate & $3(3)$ \\
Postgraduate & \\
Occupation & $35(35)$ \\
Employed & $16(16)$ \\
Retired & $15(15)$ \\
Business & $34(34)$ \\
Homemaker & \\
Monthly income (Rs) & $32(32)$ \\
Up to 5000 & $17(17)$ \\
5001-10,000 & $15(15)$ \\
10,001-15,000 & $36(36)$ \\
>15,000 & \\
Marital status & $97(97)$ \\
Married & $2(2)$ \\
Unmarried & $1(1)$ \\
Widow/widower & $0(0)$ \\
Divorced/separated &
\end{tabular}

Table 2: Distribution of subjects based on clinical characteristics, $n=100$

\begin{tabular}{ll}
\hline Clinical data & Frequency (f) (\%) \\
\hline Duration of cardiac illness (Year) & \\
$<1$ & $16(16)$ \\
$1-5$ & $40(40)$ \\
$>5$ & $44(44)$ \\
Family history of cardiac illness & $21(21)$ \\
Yes & $79(79)$ \\
No & \\
Smoking habits & $9(9)$ \\
Yes & $64(64)$ \\
No & $27(27)$ \\
Stopped & \\
Habit of alcoholism & $11(11)$ \\
Yes & $55(55)$ \\
No & $34(34)$ \\
Stopped & \\
BMI & $2(2)$ \\
Underweight $(<18.50)$ & $37(37)$ \\
Normal range $(18.50-24.99)$ & $47(47)$ \\
Overweight $(\geq 25.0)$ & $14(14)$ \\
Obese $(\geq 30.0)$ & \\
\hline
\end{tabular}

BMI: Body mass index 
The data presented in Fig. 1 showed that 65 (65\%) subjects had the habit of snoring.

The data presented in Fig. 2 showed that nearly 51 (51\%) subjects were on conservative management, whereas 39 (39\%) had undergone percutaneous transluminal coronary angioplasty for CVDs.

The data illustrated in Fig. 3 showed that majority of the subjects, 70 (70\%), were diagnosed with MI, $18(18 \%)$ of the subjects had other forms of cardiac dysfunction, followed by $6(6 \%)$ subjects having heart blocks, with only of $4(4 \%)$ and $2(2 \%)$ subjects diagnosed with cardiomyopathy and heart failure among patients with CVD.

Table 3 enumerates the data of sleep disturbances among patients with CVD, and among 100 subjects, 80 (80\%) of them had sleep disturbances. $56(56 \%)$ had remarkably mild sleep disturbances, moderate sleep disturbances were seen in 20 (20\%), and 4 (4\%) subjects with CVD complained of severe sleep disturbances in the previous month.

Table 4 enumerates the level of sleep disturbances among subjects with the duration of cardiac illness. Among the 100 subjects, 16 subjects had $<1$ year of cardiac illness, of which 9 subjects had mild sleep disturbances, subjects with $>5$ years of cardiac illness 20 subjects had mild sleep disturbances, and 13 subjects had moderate sleep disturbances. Majority of the subjects, 56 (56\%), had mild sleep disturbances, of which $27(48.2 \%)$ subjects had cardiac illnesses within 1-5 years' duration.

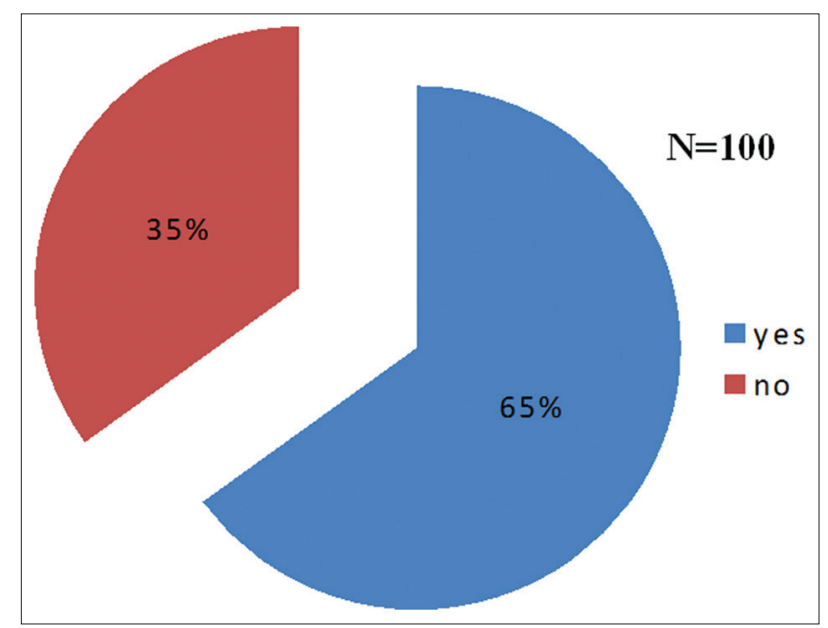

Fig. 1: Pie diagram showing habit of snoring among patients with cardiovascular diseases

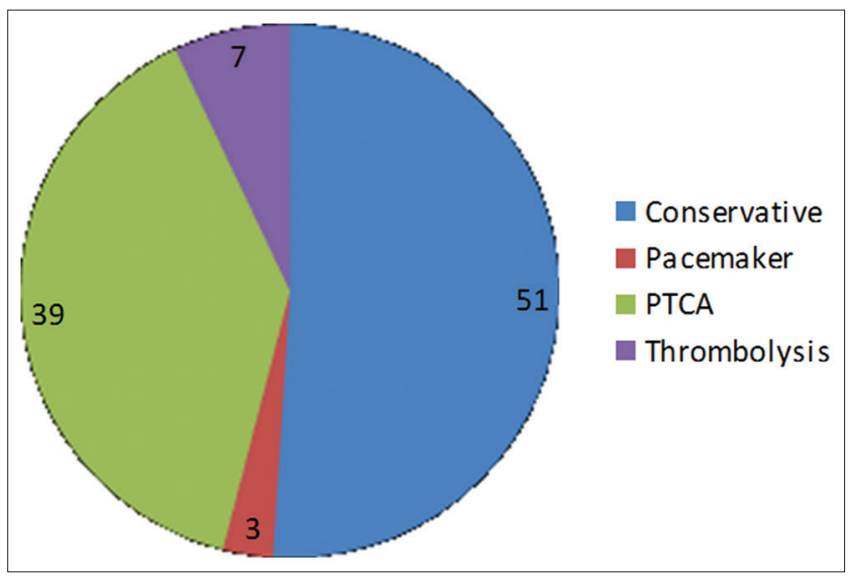

Fig. 2: Pie diagram showing the intervention undergone among the patients with cardiovascular disease
Section II: Experience of sleep disturbances among patients with CVD The data presented in Table 5 showed that, among 100 subjects, $80(80 \%)$ subjects mentioned symptoms of insomnia, 60 (60\%) subjects had restless leg syndrome (RLS), 68 (68\%) subjects complained of fatigue and nightmares, and $47(47 \%)$ and 65 (65\%) subjects were having dozing and snoring, respectively.

\section{Section III: Quality of sleep among patients with CVDs}

The data presented in Table 6 regarding the quality of sleep of patients with CVD showed that the global PSQI mean score is 6.41. Approximately more than half $66(66 \%)$ subjects rated that their sleep quality is fairly good, whereas $17(17 \%)$ subjects rated fairly bad. $38(38 \%)$ subjects had 16-30 min of sleep latency, but 14 (14\%) subjects took $>60$ min to fall asleep from lying down with a mean sleep latency of $96 \mathrm{~min} .6-7 \mathrm{~h}$ of sleep duration was reported by 42 (42\%) subjects, 20 (20\%) subjects reported 5-6 h of sleep duration, and $14(14 \%)$ subjects had only $<5 \mathrm{~h}$ of sleep. The habitual sleep efficacy was $>85 \%$ for $61(61 \%)$ subjects, whereas the sleep efficacy between $65 \%$ and $74 \%$ and $<65 \%$ was present in $10(10 \%)$ subjects each. $71(71 \%)$ subjects reported mild sleep disturbances and $23(23 \%)$ subjects rated moderate sleep disturbances; moreover, 2 (2\%) subjects had severe sleep disturbances. Only 3 (3\%) subjects used sleep medications three or more times in a week. Among the 100 subjects, 56 (56\%) subjects complained of daytime dysfunction, of which, $34(34 \%)$ subjects reported slight daytime dysfunction, whereas $5(5 \%)$ subjects mentioned severe daytime dysfunction.

The data presented in Fig. 4 revealed that majority of the subjects, $52(52 \%)$, reported score between 0 and 5 indicating good quality of sleep and only 48 (48\%) had score between 6 and 21 identifying poor quality of sleep.

Section IV: Association of sleep disturbances and selected variables The association computed using Chi-square between the level of sleep disturbances and selected demographic variables is presented in Table 7,

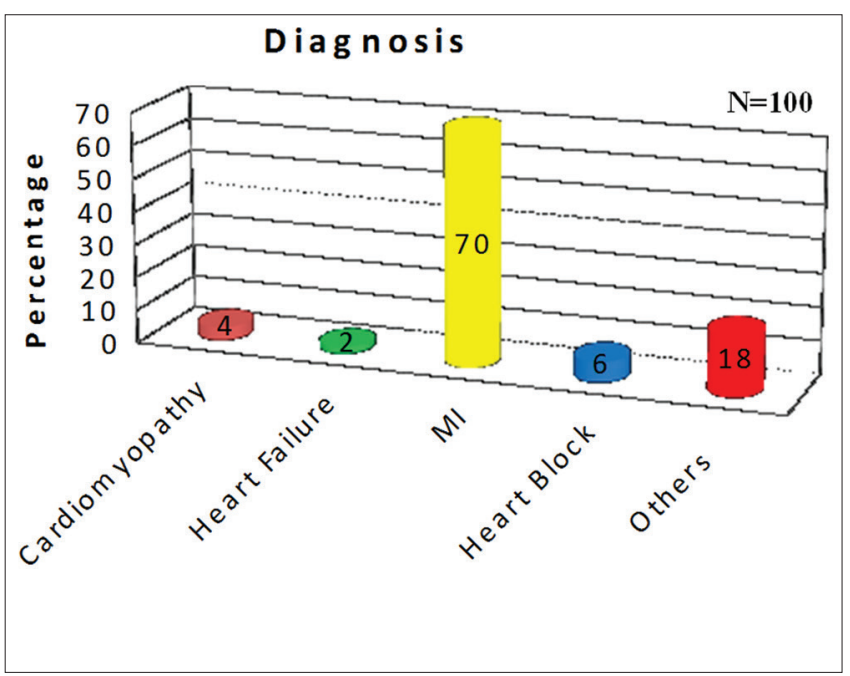

Fig. 3: Cylindrical bar diagram showing the diagnosis of patients with cardiovascular diseases

Table 3: Level of sleep disturbances among patients with CVD, $\mathbf{n}=\mathbf{1 0 0}$

\begin{tabular}{ll}
\hline Level of sleep disturbances & Frequency (f) (\%) \\
\hline No disturbances & $20(20)$ \\
Mild disturbances & $56(56)$ \\
Moderate disturbances & $20(20)$ \\
Severe disturbances & $4(4)$ \\
Very severe disturbances & $0(0)$ \\
\hline
\end{tabular}

CVD: Cardiovascular diseases 
Table 4: Distribution of subjects based on duration of cardiac illness and sleep disturbances, $n=100$

\begin{tabular}{|c|c|c|c|c|}
\hline \\
\hline \multicolumn{5}{|c|}{$\begin{array}{l}\text { Sleep disturbances } \\
\text { Duration of cardiac illness (Year) No disturbances } f(\%) \text { Mild disturbances } f(\%) \text { Moderate disturbances } f(\%) \text { Severe disturbances } f(\%)\end{array}$} \\
\hline$<1$ & $3(15)$ & 9 (16.1.48) & $3(15)$ & $1(25)$ \\
\hline 1.5 & $8(40)$ & $27(2)$ & $4(20)$ & $1(25)$ \\
\hline$>5$ & $9(45)$ & 20 (35.7) & $13(65)$ & $2(50)$ \\
\hline
\end{tabular}

Table 5: Distribution of subjects with CVD based on the clinical symptoms of sleep disturbances, $n=100$

\begin{tabular}{ll}
\hline Clinical symptoms & Frequency (f) (\%) \\
\hline Insomnia & $80(80)$ \\
RLS & $60(60)$ \\
Fatigue & $68(68)$ \\
Nightmares & $68(68)$ \\
Dozing & $47(47)$ \\
Snoring & $65(65)$ \\
\hline
\end{tabular}

CVD: Cardiovascular diseases, RLS: Restless leg syndrome

Table 6: Distribution of subjects based on the quality of sleep, $\mathrm{n}=\mathbf{1 0 0}$

\begin{tabular}{|c|c|c|}
\hline Sleep Quality & Frequency (f) (\%) & Mean \pm SD \\
\hline Subjective sleep quality & & $1.31 \pm 0.873$ \\
\hline Very good & $10(10)$ & \\
\hline Fairly good & $66(66)$ & \\
\hline Fairly bad & $7(7)$ & \\
\hline Very bad & $17(17)$ & \\
\hline Sleep latency & & $0.96 \pm 1.024$ \\
\hline 0 (<15 min $)$ & $40(40)$ & \\
\hline $1-2(16-30 \mathrm{~min})$ & $38(38)$ & \\
\hline $3-4(31-60 \mathrm{~min})$ & $8(8)$ & \\
\hline $5-6(>60 \mathrm{~min})$ & $14(14)$ & \\
\hline Sleep duration & & $1.24 \pm 0.976$ \\
\hline$>7 \mathrm{~h}$ & $24(24)$ & \\
\hline $6-7 \mathrm{~h}$ & $42(42)$ & \\
\hline $5-6 \mathrm{~h}$ & $20(20)$ & \\
\hline$<5 \mathrm{~h}$ & $14(14)$ & \\
\hline Habitual sleep efficacy(\%) & & $0.69 \pm 1.012$ \\
\hline$>85$ & $61(61)$ & \\
\hline $75-84$ & $19(19)$ & \\
\hline $65-74$ & $10(10)$ & \\
\hline$<65$ & $10(10)$ & \\
\hline Sleep disturbances & & $1.23 \pm 0.548$ \\
\hline 0 & $4(4)$ & \\
\hline $1-9$ & $71(71)$ & \\
\hline $10-18$ & $23(23)$ & \\
\hline $19-27$ & $2(2)$ & \\
\hline Use of sleep medications & & $0.15 \pm 0.592$ \\
\hline Not during the past month & $93(93)$ & \\
\hline Less than once a week & $2(2)$ & \\
\hline Once or twice a week & $2(2)$ & \\
\hline $\begin{array}{l}\text { Three or more times a } \\
\text { week }\end{array}$ & $3(3)$ & \\
\hline Daytime dysfunction & & $0.83 \pm 0.888$ \\
\hline 0 & $44(44)$ & \\
\hline $1-2$ & $34(34)$ & \\
\hline $3-4$ & $17(17)$ & \\
\hline $5-6$ & $5(5)$ & \\
\hline
\end{tabular}

SD: Standard deviation

and the data presented depict that there was association between gender and sleep disturbances $(\mathrm{p}<0.05)$, but there was no significant association between sleep disturbances and other demographic variables.

Section V: Association of Sleep Disturbances and Quality of Sleep The data presented in Table 8 showed that there is a highly significant association between sleep disturbances and quality of sleep 0.0001 $(\mathrm{p}<0.001)$

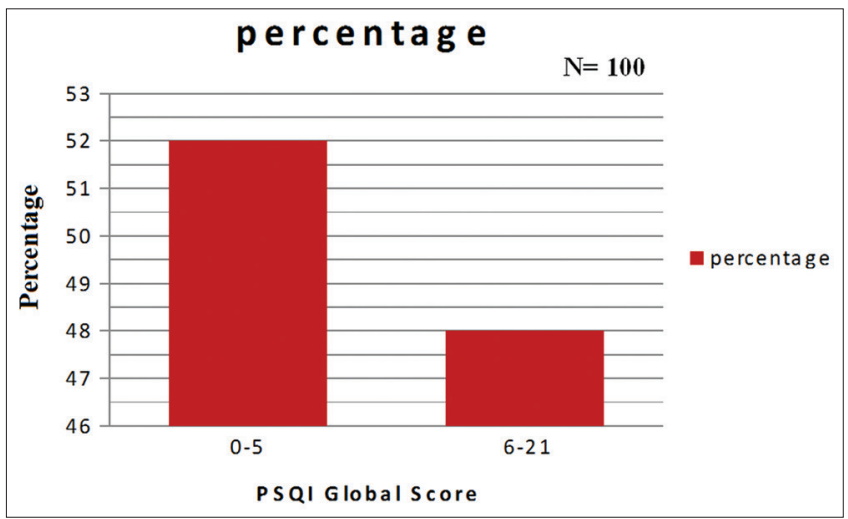

Fig. 4: Bar diagram showing the Pittsburgh sleep quality index global score of patients with cardiovascular diseases

\section{DISCUSSION}

The present study findings implicate that the subjects with CVD were of the age group of 36-75 years and $80(80 \%)$ subjects had sleep disturbances with majority of the subjects $56(56 \%)$ having mild sleep disturbances, and only 4 (4\%) had severe sleep disturbances. Majority of the $80(80 \%)$ subjects had reported manifestations of insomnia, followed by $68(68 \%)$ subjects complained of both fatigue and nightmares; moreover, snoring was reported by 65 (65\%) subjects and $60(60 \%)$ subjects mentioned about manifestations of RLS. Moreover, the subjects with cardiomyopathy showed a significant association of sleep disturbances $(\mathrm{p}<0.001)$. It was worth noticing sleep disturbances present nearly more than half of the subjects with CVD at various level from mild to severe.

The study findings are supported by Michal et al. who reported that sleep disturbances were present in $73.6 \%$ of subjects out of 10,000 patients with CVD aged between 35 and 74 years [10].

Another study reported by Shankar A, on insufficient rest or sleep and its relation to CVD also supported the study, where $11 \%$ reported all 30 days of insufficient sleep in the past month [11]. In comparing the present study with the reported studies, it can be interpreted that the prevalence of sleep disturbances occurs in subjects with CVD, which ranged from 55 to $65 \%$.

A cross-sectional study in 2017 on prevalence and determinants of insomnia after a MI among 209 subjects was conducted by Da Costa et al. The findings showed that overall $36 \%$ of the sample reported clinical symptoms of insomnia. Among the patients after MI, $62.7 \%$ subjects which was a higher proportion were experiencing insomnia with depressed mood when compared to good sleepers (13.4\%) [12]. This reported study findings support the present study, indicating that insomnia is a major concern of sleep disturbances among CVD patients.

From the above studies, it is evident that sleep disturbances are present among patients with CVDs. Sleep disturbances had increased risk of developing or dying from CHD.

The results of this study show that, among the 100 subjects with CVDs, about $48(48 \%)$ had poor sleep quality, whereas 52 (52\%) have good sleep quality and the global PSQI mean score is 6.41. 34 (34\%) subjects 
Table 7: Association between sleep disturbances and selected demographic variables, $\mathbf{n = 1 0 0}$

\begin{tabular}{|c|c|c|c|c|c|c|c|c|c|c|c|}
\hline \multirow{2}{*}{$\begin{array}{l}\text { Demographic Variables } \\
\text { Age (in years) }\end{array}$} & \multicolumn{2}{|c|}{$\begin{array}{l}\text { No } \\
\text { disturbances } \\
\text { f (\%) }\end{array}$} & \multicolumn{2}{|c|}{$\begin{array}{l}\text { Mild } \\
\text { disturbances } \\
\text { f(\%) }\end{array}$} & \multicolumn{2}{|c|}{$\begin{array}{l}\text { Moderate } \\
\text { disturbances } \\
\text { f(\%) }\end{array}$} & \multicolumn{2}{|c|}{$\begin{array}{l}\text { Severe } \\
\text { disturbances } \\
\text { f(\%) }\end{array}$} & \multirow{2}{*}{$\begin{array}{l}\chi^{2} \\
10.462\end{array}$} & \multirow{2}{*}{$\begin{array}{l}\text { df } \\
9\end{array}$} & \multirow{2}{*}{$\begin{array}{l}\text { p value } \\
0.314^{\text {ns }}\end{array}$} \\
\hline & & & & & & & & & & & \\
\hline $36-45$ & 1 & 5 & 4 & 7.1 & 0 & 0 & 0 & 0 & & & \\
\hline $46-55$ & 8 & 40 & 10 & 17.9 & 8 & 40 & 1 & 25 & & & \\
\hline $56-65$ & 10 & 50 & 35 & 62.5 & 12 & 60 & 2 & 50 & & & \\
\hline $66-75$ & 1 & 5 & 7 & 12.5 & 0 & 0 & 1 & 25 & & & \\
\hline Gender & & & & & & & & & 8.312 & 3 & $0.040^{*}$ \\
\hline Male & 15 & 75 & 44 & 78.6 & 11 & 55 & 1 & 25 & & & \\
\hline Female & 5 & 25 & 12 & 21.4 & 9 & 45 & 3 & 75 & & & \\
\hline Education & & & & & & & & & 12.383 & 12 & $0.415^{\mathrm{ns}}$ \\
\hline Primary & 1 & 5 & 7 & 12.5 & 0 & 0 & 0 & 0 & & & \\
\hline High school & 9 & 45 & 22 & 39.3 & 15 & 75 & 3 & 75 & & & \\
\hline Pre-degree/plus-two/equivalent & 4 & 20 & 10 & 17.9 & 1 & 5 & 1 & 25 & & & \\
\hline Graduate & 5 & 25 & 15 & 26.8 & 4 & 20 & 0 & 0 & & & \\
\hline Postgraduate & 1 & 5 & 2 & 3.6 & 0 & 0 & 0 & 0 & & & \\
\hline Marital status & 0 & & & & & & & & 5.604 & 6 & $0.469^{\text {ns }}$ \\
\hline Single & 20 & 0 & 2 & 3.6 & 0 & 0 & 0 & 0 & & & \\
\hline Married & 0 & 100 & 54 & 96.4 & 19 & 95 & 4 & 100 & & & \\
\hline Widow/widower & & 0 & 0 & 0 & 1 & 5 & 0 & 0 & & & \\
\hline
\end{tabular}

Table 8: Association of sleep disturbances and quality of sleep, $n=100$

\begin{tabular}{|c|c|c|c|c|c|c|c|}
\hline Type of sleep disturbances quality of sleep & Good & (f) & Poor & (f) & $\chi^{2}$ & df & p value \\
\hline No disturbances & 18 & 90 & 2 & 10 & 24.164 & 3 & $0.0001 *$ \\
\hline Mild disturbances & 30 & 53.6 & 26 & 46.4 & & & \\
\hline Moderate disturbances & 4 & 20 & 16 & 80 & & & \\
\hline Severe disturbances & 0 & 0 & 4 & 100 & & & \\
\hline
\end{tabular}

*Highly significant $(\mathrm{p}<0.001)$

mentioned $<6 \mathrm{~h}$ of sleep duration, and the findings also show that poor quality of sleep was present among subjects with $<6 \mathrm{~h}$ of sleep odds ratio $=0.07$ (95\% confidence interval: 4.40-64.05, $\mathrm{p}<0.0001)$ when comparing with subjects who are sleeping $6-8 \mathrm{~h}$, and there is a highly statistically significant association between short sleep duration $<6 \mathrm{~h}$ with quality of sleep.

The study findings were supported on the result of the retrospective control study conducted by Sharma, which showed that both poor quality of sleep and short sleep duration should be independently associated with CAD. Poor sleep quality (PSQI >5) was 16.62 (9.13-30.28) among 352 adult subjects (176 controls and 176 cases) [13]. This suggests that poor sleep quality and short sleep duration may be important modifiable CAD risk factors in the Indian population.

Chen HM, conducted a study on self-reported health-related quality of life and sleep disturbances among 125 heart failure participants. PSQI was used, and the mean score is 9.06 .93 (74.4\%) participants were identified as poor sleepers, which is justifying the results of the present study [14].

Andrechuk and Ceolim study on sleep quality in patients with AMI among 113 subjects reported that $71.7 \%$ of subjects with AMI had frequent poor sleep quality according to the PSQI [7].

On comparing the study results with the above-mentioned study, it is evident that poor sleep quality was present in patients with CVDs. In the present study, 48 (48\%) had poor quality of sleep and it can be interpreted as the quality of sleep among patients with CVD is poor. Many studies shown the relationship between sleep apnea and CVD [15].

\section{CONCLUSION}

The epidemiological and pathophysiological literature indicate that there may be a causal link between primary sleep abnormalities and cardiovascular and metabolic diseases. Moreover, it is not adequately addressed by the health-care fraternity and patients are also unaware about its importance.

Further understanding of specific pathophysiological pathways linking to sleep disorders to CVD is important for developing therapeutic strategies, and the present study provides an insight to the health-care community which has an important implication for cardiovascular health.

\section{AUTHORS' CONTRIBUTIONS}

Conceptualization and study design - Neenu Merin and Regina Antony. Data collection, sample analysis, and performing the experiment - Neenu Merin. Preparation of manuscript - Neenu Merin and Regina Antony. Statistical Analysis - Neenu Merin and Regina Antony. Proofreading the manuscript - Regina Antony. All authors read and approved the final manuscript.

\section{CONFLICTS OF INTEREST}

All authors have none to declare.

\section{SOURCE OF FUNDING}

Self.

\section{ETHICAL CLEARANCE}

Research proposal was presented before the research committee of Amrita College of Nursing and obtained approval. Later ethical clearance obtained from the ethical committee of Amrita Institute of Medical Sciences, Kochi.

\section{REFERENCES}

1. Chintamani M, Mani M. Lewis's Medical Surgical Nursing: Assessment and Management of Clinical Problem. New Delhi: Elseveir; 2011.

2. Sabanayagam C, Shankar A. Sleep duration and cardiovascular disease: Results from the national health interview survey. Sleep 2010;33:1037-42. 
3. Tamargo J, Castellano JM, Fuster V. The fuster-CNIC-ferrer cardiovascular polypill: A polypill for secondary cardiovascular prevention. Int J Cardiol 2015;201 Suppl 1:S15-22.

4. Gandhi A, Ayyappan P, Sahana C, Poovizhi S, Sivasakthi K. Knowledge of modifiable risk factors of heart disease among patients with cardiovascular risk. Asian J Pharm Clin Res 2017;10:99-102.

5. National Sleep Foundation. How Sleep Deprivation Affects Your Heart; 2011. Available from: https://www.sleepfoundation.org/sleep-news/ how-sleep-deprivation-affects-your-heart. [Last cited on 2012 Jun 29].

6. Roth GA, Johnson C, Abajobir A, Abd-Allah F, Abera SF, Abyu G, et al. Global, regional, and national burden of cardiovascular diseases for 10 causes, 1990 to 2015. J Am Coll Cardiol 2017;70:1-25.

7. Andrechuk CR, Ceolim MF. Sleep quality in patients with acute myocardial infarction. Texto Contexto-Enfermagem 2015;24:1104-11.

8. Jhawat V, Gupta S, Agarwal BK, Roy P, Saini V. Prevalence and risk factors of essential hypertension and new onset of diabetes in essential hypertension in rural population of Haryana. Int J Pharm Pharm Sci 2018;10:142.

9. Rupavate S. Heart Disease in India-6 Shocking Facts you Should Know. Available from: http://www.thehealthsite.com/diseases-conditions/heartdisease-in-india-6- shocking-facts-you-should-know. [Last accessed on
2015 Feb 24].

10. Michal M, Wiltink J, Kirschner Y, Schneider A, Wild PS, Münzel T, et al. Complaints of sleep disturbances are associated with cardiovascular disease: Results from the gutenberg health study. PLoS One 2014;9:e104324.

11. Shankar A, Syamala S, Kalidindi S. Insufficient rest or sleep and its relation to cardiovascular disease, diabetes and obesity in a national, multiethnic sample. PLoS One 2010;5:e14189.

12. Da Costa D, Allman AA, Libman E, Desormeau P, Lowensteyn I, Grover S, et al. Prevalence and determinants of insomnia after a myocardial infarction. Psychosomatics 2017;58:132-40.

13. Sharma M, Sawhney JP, Panda S. Sleep quality and duration-potentially modifiable risk factors for coronary artery disease? Indian Heart $\mathrm{J}$ 2014;66:565-8.

14. Chen HM, Clark AP, Tsai LM, Lin CC. Self-reported health-related quality of life and sleep disturbances in Taiwanese people with heart failure. J Cardiovasc Nurs 2010;25:503-13.

15. Instantaneous Heart Rate as a Robust Feature for Sleep Apnea Severity Detection Using Deep Learning. 2017 IEEE EMBS International Conference on Biomedical and Health Informatics, BHI 2017; 2017. 